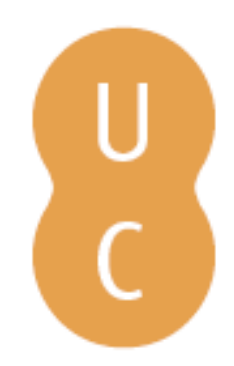

\title{
nombalina
}

\section{Crise e sentido}

Autor(es): Umbelino, Luís António

Publicado por: Imprensa da Universidade de Coimbra

URL

persistente:

URI:http://hdl.handle.net/10316.2/30723

DOI:

DOI:http://dx.doi.org/10.14195/978-989-26-0574-6_3

Accessed : $\quad$ 26-Apr-2023 16:25:50

A navegação consulta e descarregamento dos títulos inseridos nas Bibliotecas Digitais UC Digitalis, UC Pombalina e UC Impactum, pressupõem a aceitação plena e sem reservas dos Termos e Condições de Uso destas Bibliotecas Digitais, disponíveis em https://digitalis.uc.pt/pt-pt/termos.

Conforme exposto nos referidos Termos e Condições de Uso, o descarregamento de títulos de acesso restrito requer uma licença válida de autorização devendo o utilizador aceder ao(s) documento(s) a partir de um endereço de IP da instituição detentora da supramencionada licença.

Ao utilizador é apenas permitido o descarregamento para uso pessoal, pelo que o emprego do(s) título(s) descarregado(s) para outro fim, designadamente comercial, carece de autorização do respetivo autor ou editor da obra.

Na medida em que todas as obras da UC Digitalis se encontram protegidas pelo Código do Direito de Autor e Direitos Conexos e demais legislação aplicável, toda a cópia, parcial ou total, deste documento, nos casos em que é legalmente admitida, deverá conter ou fazer-se acompanhar por este aviso.

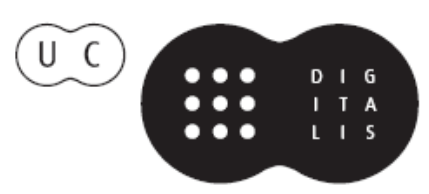




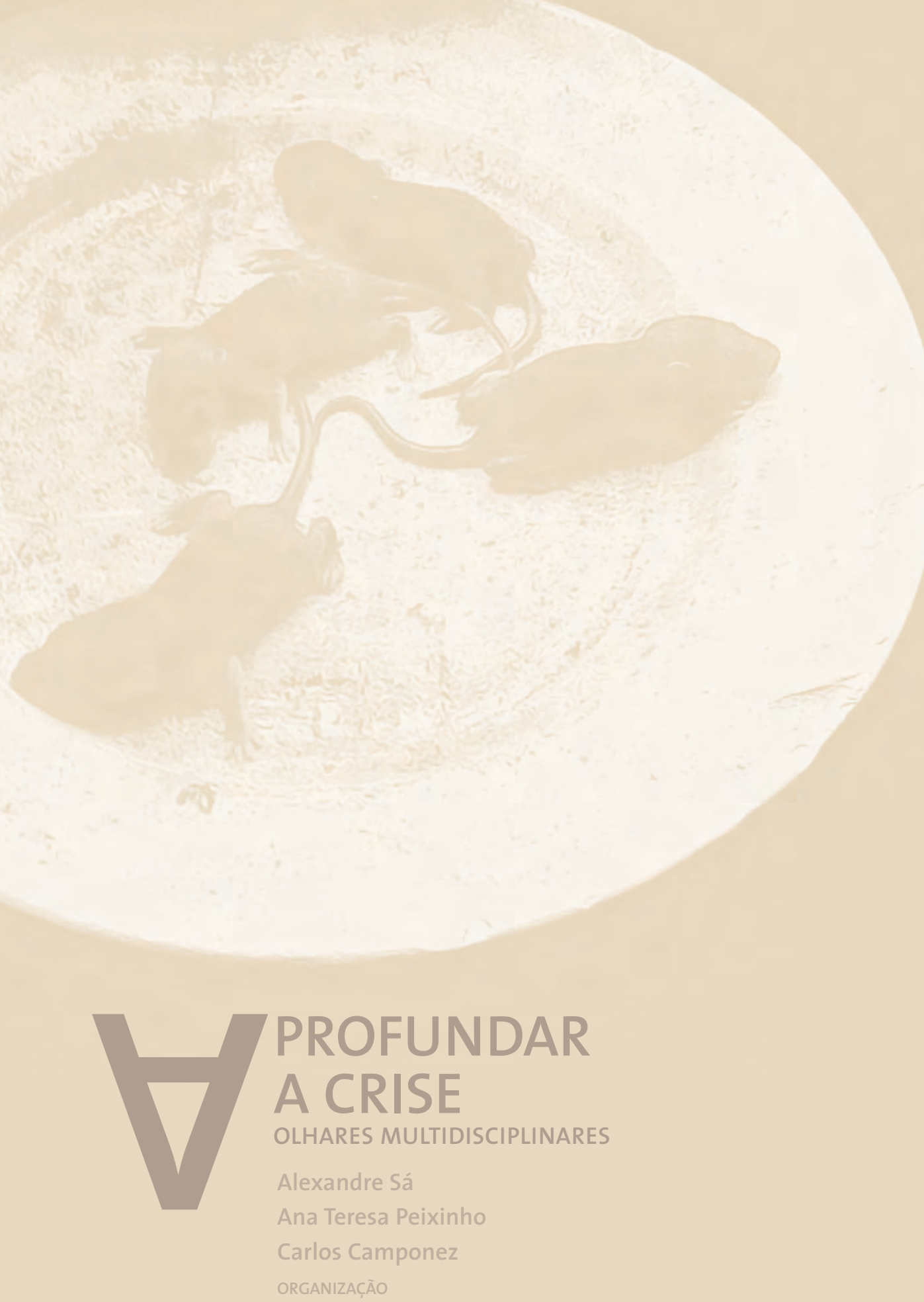


Luís António Umbelino

FLUC - LIF

\section{Crise e Sentido}

\section{Intróito}

Nesta ocasião em que o Departamento de Filosofia, Comunicação e Informação se reúne em colóquio para meditar o tema da crise, vale a pena recordar as linhas iniciais do ensaio "Filosofia e Crise Atual de Sentido", com o qual o saudoso Prof. Miguel Baptista Pereira inaugurava a obra coletiva de 1986 Tradição e Crise. No seu estilo denso e provocador, afirmava: "Construir ou ensinar filosofia não é desertar do presente problemático que nos aflige (...) mas participar sem repetir na reserva de sentido do passado ou no seu potencial de futuro." ${ }^{53}$ A atualidade de tais palavras reforça-se hoje na contraluz de um tempo angustiado que reclama, mais do que nunca, a reabilitação das melhores possibilidades incumpridas do passado, o reforço das energias do presente e a projeção de umas e outras na construção de um futuro alternativo. Neste esforço coletivo, deverá a meditação filosófica desempenhar o seu papel. E este poderá ser, desde logo, o de pensar com densidade o próprio conceito de "crise", assim disponibilizando instrumentos teóricos suficientemente vigorosos para o aprofundar.

\section{Um critério existencial}

No cenário quase totalitário da contemporânea crise dita financeira e económica, mas que também já foi classificada de "ideológica", "cultural" e "ética", uma

53 Pereira, M.B., "Filosofia e Crise Actual de Sentido", in AAVV, Tradição e Crise, FLUC, Coimbra, 1986, p. 5. 
pergunta quase nunca é formulada: do que falamos exatamente quando falamos de crise? Isto é: por que razão e seguindo que critério somos levados a caracterizar determinado estado, contexto, situação, período como sendo "de crise"?

Não se trata de uma questão fácil, desde logo pelo facto de se utilizar o termo "crise" para qualificar uma grande variedade de fenómenos aparentemente diferentes. Basta assistir a um qualquer programa noticioso para escutar expressões como: "a crise em que o país está mergulhado", a "crise no médio-oriente adensa-se", "há uma crise de talentos", "continua a crise de vocações", regista-se uma "crise de resultados", "o casamento está em crise", "a crise do saber", etc. Acresce a esta variedade de usos o facto de cada um deles poder ser configurado por uma multiplicidade de modelos de referência. O filósofo francês P. Ricoeur viu-o bem e por isso começa o seu artigo "La crise, un phénomène spécifiquement moderne?" ${ }^{4}$ elencando os principais conceitos "regionais" de crise, à procura de significados básicos que, presentes nos vários modos de uso do conceito, sirvam de ancoragem à análise. Assim, analisa o modelo médico da crise, o modelo do desenvolvimento psico-fisiológico, o modelo que denomina, na esteira de Kant, de cosmopolítico, o modelo de crise fornecido pela história das ciências, ilustrado pela obra de Th. Kuhn, e finalmente o modelo da crise dita "económica", hoje representada pelos problemas decorrentes da desregulação dos mercados financeiros que se globalizam ao mesmo tempo que se tornam perigosamente autónomos em relação a qualquer controlo político democrático.

De qualquer um destes modelos é possível fazer derivar um certo grau de generalização capaz de nos oferecer algumas orientações para responder à nossa questão inicial sobre o sentido da crise. Consideremos dois exemplos de entre os apontados: é possível usar o termo crise por referência ao "modelo médico" de crise e, assim, o termo é associado a uma doença - súbita -, a um contexto patológico - anormal - revelado por sintomas precisos de sofrimento ou mal-estar, que reclamam diagnóstico e intervenção especializada. É assim que podemos estabelecer analogias do tipo: "o país está doente", "esta situação já não tem cura", etc. Mas se considerarmos o modelo científico ilustrado por Kuhn, uma situação de crise já é entendida como situação imprescindível ao avanço do

54 RICOEUR, P., "La crise, un phénomène spécifiquement moderne?", in Revue de théologie et de philosophie, 120 (1988), p. 1-19, consultado em http://www.fondsricoeur.fr/photo/crise(4).pdf 
conhecimento e à mudança de paradigmas. É assim que podemos encontrar no discurso dos mais otimistas a ideia de que "a crise mudará tudo", a convicção de que "agora temos de pensar de outra forma", ou a crença em que "a situação nunca mais será a mesma”.

O problema dos modelos regionais de crise é que a generalização de cada um deles tem limites que o impedem de se tornar critério único. A nossa questão inicial, portanto, resiste e uma outra abordagem é reclamada. O critério deve procurar-se noutro lugar.

Neste sentido, pela nossa parte, gostaríamos de sugerir a seguinte possibilidade: para entendemos determinada situação fora de nós e à nossa volta como "crise", é forçoso que encontremos primeiro "em nós" um modelo interior que permita, por analogia, viver, experimentar e compreender como crise determinado estado de coisas. É o que, a nosso ver, Ricoeur nos autoriza a pensar quando, ao procurar uma aproximação holística e não apenas analítica e fragmentada ao conceito de crise ${ }^{55}$, descobre "um encorajamento neste sentido nas filosofias existenciais que encontram a noção de crise como estrutura permanente da bumana conditio." 56 Neste contexto, são os nomes de Max Scheler, Paul Landsberg e Emanuel Mounier que surgem sob a pena do filósofo de Valence para recordar a que ponto "o conflito, a rutura, o risco" fazem parte da "conceção militante do homem comprometido". Segundo Paul Landsberg, nomeadamente, a pessoa desvenda-se sob os traços dramáticos de um ritmo existencial traçado entre "as forças da vida que a atraem para um êxtase negro e as forças espirituais que a atraem para um êxtase superior"; e, neste sentido, pode afirmar-se que a crise é "o entre dois, constitutivo da coragem de existir", não sendo descabido concluir que o "processo de personalização, enquanto conquista da singularidade e da diferença" parece, de algum modo, conter "em embrião todas as figuras parciais da crise" ${ }^{57}$.

Dir-se-ia, então, que um primeiro "barómetro" da crise se encontra na constituição oscilante de uma individualidade que luta por se reapossar de si própria e da sua ação na contraluz da possibilidade de não o conseguir sempre em todos os momentos - uma individualidade que, portanto, procura afirmar-se

\footnotetext{
55 Ibidem, p. 11

56 Ibidem, p. 11

57 Ibidem, p. 11
} 
mas constantemente se pode desolar de si própria, que procura perseverar no seu centro mas recorrentemente se pode arruinar, que procura conquistar-se mas frequentemente se reconhece devastada no centro do seu próprio existir.

A ser correta esta nossa assunção, o reconhecimento de dada situação social, política, ética, etc., como "de crise" terá sempre como primeiro critério, como primeiro modelo, um referencial autobiográfico - a história de uma vida que persevera no fio oscilante de um existir sempre precário, sempre construído sem pontos de apoio fixos dados à partida ou de uma vez por todas.

Pelo seu incomparável valor filosófico e carácter pioneiro, parece-nos ter a este respeito importância de exemplo paradigmático o texto do Journal intime de Maine Biran, filósofo francês injustamente esquecido que até ao ano da sua morte, em 1824, não cessou de testemunhar e interrogar filosoficamente as crises diárias da vigência perseverante da posse de si. Os exemplos encontram-se em praticamente todas as páginas desse texto tão especial. Anotemos apenas um exemplo: "Grateloup, 3 de setembro: (...) A mudança de temperatura afetou-me. Apanhei uma constipação que abate singularmente as minhas faculdades e me tira todo o equilíbrio, toda a firmeza de pensamento." 58 Em traços melancólicos, o filósofo de Bergerac espanta-se com a inconstância das condições propícias ao pensamento, surpreende-se com a sua contingência, eclipses e intermitências que parecem acompanhar as mais prosaicas circunstâncias diárias: uma digestão pesada, mudanças súbitas do clima, etc. E filosoficamente interroga-os com precisão: "a que ponto dependo eu de mim próprio?" Por que razão "não pensamos sempre"? Que significa esta estranha condição de por vezes "cessar de ser eu"?

As origens da recorrente crise da posse de si situa-as Biran no "fluxo perpétuo"59 de uma matéria sensitiva que se sucede, alterna e varia no corpo vivo da organização podendo interferir constante e continuamente ${ }^{60}$, com a "direção das nossas ideias e dos nossos pecados", da nossa vontade e do nosso corpo próprio. Assim varia a meteorologia da interioridade biraniana: tomba a organização na astenia e logo se regista "um dia triste; todas as minhas boas

\footnotetext{
58 MAINE de BIRAN, Journal intime, II, ed. La Baconnière, Neuchatel, 1955, p. 154.

59 Veja-se, por exemplo, MAINE de BIRAN, De l'aperception immédiate. Mémoire de Berlin, in Euvres de Maine de Biran, t. IV, ed. Vrin, Paris, p. 137, n.

60 Veja-se, por exemplo, MAINE de BIRAN Essai sur les fondements de la psychologie, II, Euvres, t. VII-2, ed. Vrin, Paris, p. 202.
} 
disposições vitais se desvaneceram; a humidade penetra-me e entristece-me" ${ }^{\prime 61}$; impera a inconsistência do corpo afetivo e há que registar os dias passados "num estado penoso de tristeza, de desencorajamento, de dificuldade e quase de ausência de vida" ${ }^{2}$; alvoroça-se o jogo das imagens e fluxos afetivos - que parece ter o seu centro no estômago ${ }^{63}$ - e eis que afluem todas as inconstâncias do humor, todas as faces do devaneio alucinado, todos os males da "doença da distração" "; ; abate-se em movimentos nervosos e dormentes a "máquina", e logo parecemos, no tumulto do mundo, os magnetizadores de nós próprios, cada qual deambulando "distraído e como um sonâmbulo neste mundo dos assuntos"65.

Esta última referência (recorrente) merece ser sublinhada. Biran reconhece que a crise da posse de si não é estranha à presença no "mundo dos assuntos", às influências da sociedade, à "órbita" dos outros, às transformações constantes do mundo da política. O barómetro do continente da interioridade do qual Biran desejou ser o "Colombo metafísico" também oscila ao ritmo da sociedade e das influências simpáticas dos outros, também balança com as cadências da vida social, com as suas convulsões, exigências e imposições. No centro de uma teoria da vida afetiva, e a partir da constatação da crise da posse de si, que o biranismo encontra o terreno da ética e da reflexão social e política.

Com esse terreno do "mundo dos assuntos", no entanto, Maine Biran manterá sempre uma relação paradoxal. Por um lado, relata diariamente os males que dele colhe a sua frágil saúde, os desajustamentos que o seu temperamento patenteia; por outro lado, não deixará de procurar uma vida política e uma presença pública. Várias entradas do Journal podem ilustrá-lo, mas eventualmente nenhuma de modo mais eloquente do que o episódio do "peditório para os pobres de Saint Sauveur". A Sra Duquesa de Rohan, acompanhada de Castel-Bajac, conhecido de Biran, vai a casa deste último para lhe pedir que contribua para os pobres e o nosso filósofo, nesse dia indisposto, sem firmeza, nervoso, contribui com seis francos que tinha preparado por esperar já a chegada da Duquesa. Ora, uma palavra da sua visita, referindo-se a outras pessoas que haviam contribuído com

\footnotetext{
61 MAINE de BIRAN, Journal, II, p. 163

62 Ibidem, p. 205.

63 Ibidem, p. 5.

64 Ibidem, p. 21.

65 Ibidem, p. 27.
} 
um ou dois Luíses, será suficiente para que Biran imediatamente comece a pensar que a sua esmola foi vergonhosamente pequena. Fica paralisado. Nada mais fará durante o dia senão pensar neste assunto: o que pensarão dele, para mais um homem político, com responsabilidades e respeitado? Como retificar tal gesto ridiculamente avaro? Tornar-se-á na anedota da sociedade. Permanentemente inquieto chegará a passar em frente à casa da Duquesa, mas não conseguirá entrar. Não sabe o que dizer, como dizer. Apenas após o jantar, quando o acaso o leva a encontrar a benemérita e lhe diz que deseja aumentar o seu contributo, apenas então ficará descansado ${ }^{66}$.

O episódio é revelador da personalidade melancólica, depressiva e quase patologicamente insegura de Biran ; mas não é por isso que se trata de um passo importante do Journal. Ele é interessante a vários níveis. Primeiro, por nos obrigar a pensar a que ponto a vida afetiva marca a nossa primeira "entrada" no mundo e, ao mesmo tempo, a que ponto o mundo e os outros podem influir, sem controlo da nossa consciência, sobre o nosso temperamento e sobre os equilíbrios da nossa interioridade. Depois, por nos oferecer - como viu A. Antoine no seu pequeno mas estimulante texto intitulado Maine de Biran. Sujet et politique $e^{67}$ - uma significativa prefiguração do "tipo novo de homem democrático do qual Tocqueville fará magistralmente a teoria na sua segunda [parte] de Démocratie en Amérique." 68 O que caracteriza a nova sociedade americana é o facto de desenhar uma ordem sem "ordens sociais", sem classes, corporações ou privilégios de nascença e de se fundar na universalidade e igualdade dos valores individuais. O mesmo é dizer que a afirmação do "eu" passa a ser um direito universal, mas também precisamente por isso uma conquista perpétua contra a multidão de iguais; é necessário medir-nos constantemente entre todos, procurar a aceitação do outro, lutar pelo seu apoio, procurar partilhar os mesmos valores e assumir que se está sempre sob o olhar avaliador de alguém que partilha os mesmos direitos e oportunidades. Que este esforço encerra algo de perturbador é o que já Maine de Biran testemunha na primeira pessoa: "O sentimento da minha fraqueza faz com que experimente, mais do que qualquer outra, a necessidade de ser apoiado, de estar em paz com todo o mundo, de

\footnotetext{
66 Ibidem, I, p. 186.

67 ANTOINE Agnès, Maine de Biran. Sujet et politique, P. U.F., Paris, 1999, pp. 38 e ss.

68 Ibidem, pp. 41-42
} 
inspirar a benevolência de cada um (...). Quando estou na dúvida do sucesso, o medo atormenta-me; se julgo notar alguma indiferença ou menosprezo, entro em suplício; eis um escravo completo." ${ }^{" 69}$ A experiência de Biran numa sociedade em convulsão é a de se sentir fora do seu lugar e do seu tempo; sente que - diríamos, jogando com o título famoso de Max Scheler O lugar do homem no cosmos - não tem naturalmente um lugar no "cosmos" social e político. "Não conheço bem o meu lugar - escreve Biran - o instinto variável de fraqueza ou de força mostra-mo ora mais alto, ora mais baixo"70

Com Biran percebemos que o homem da sociedade, submetido ao olhar avaliador do outro ${ }^{71}$, tomado pelos cegos desígnios das simpatias, é fundamentalmente um ser inquieto, melancólico, perturbado, que constantemente se comparara com os iguais e julgando nunca estar "à altura"72, continuamente convocado pelas obrigações sociais mas "desencantado do mundo"73 na contraluz de uma ausência de pontos de apoio seguros para se conquistar a si próprio na diferença - enfim, alguém forçado a participar de uma "exterioridade" que reforça a evidência interior de que a conquista de si, o reapossamento, o perseverar no seu centro é uma tarefa penosa, árdua e cheia de dificuldades.

O sujeito biraniano traz consigo a crise. E esta corresponde ao sentimento de desequilíbrio recorrente ante a necessidade constante de superar, sob o olhar avaliador dos outros, todo o tipo de alternativas que reclamam uma decisão, de abismos que carecem de uma ligação, de ruturas que exigem uma ordem. E a insegurança constante torna-se assim pasto do pressentimento de poder "cessar de ser eu", do bloqueio ou dormência da reflexão impedindo a concentração e a posse de si e, no limite, da experiência melancólica de oscilar entre o perseverar na posse de si e o desapossamento imposto pelo fluxo de uma vida em mim sem

69 MAINE de BIRAN, Journal I, p. 198. Cf. ANTOINE Agnès, Maine de Biran ..., p. 39 e ss.

70 Ibidem, II, p. 86.

71 Ibidem, I, p. 198

72 Ibidem, II, p. 90: «Je me sens plus faible au milieu de tant d'hommes forts ; je ne me mets pas en rapport avec eux ; je cesse d'être moi sans me confondre avec les autres; le moindre signe d'opposition ou seulement d'indifférence me trouble et m'abat. Je perds toute présence d'esprit, tout sentiment et toute apparence de dignité. Je sens que les autres doivent avoir une pauvre idée de mon chétif individu et cette persuasion me rend plus chétif, plus timide et plus faible encore. Je devrais renoncer aux grandes assemblées et à la vie publique ou extérieure ; j'y suis le moins propre de tous les hommes."

73 Ibidem, II, p. 208. Cf. DEVARIEUX, A., Maine de Biran. L'individualité persévérante, Millon, 2004, p. 372. 
mim, entre as condições para se concentrar e as circunstâncias que desconcentram, magnetizam, alienam e roubam o tempo do eu.

\section{Crise, tempo e afirmação}

Com Biran encontrámos um primeiro critério em nós para perceber o que é uma crise: esse critério encontra-se ligado ao sentimento de não saber qual o nosso lugar no mundo, à insegurança de não saber sempre e em todas as circunstâncias que hierarquia de valores pode conduzir as decisões, à inquietação de não poder dominar as influências dos outros ou conseguir distinguir claramente quem são os amigos e os adversários, ao desassossego de não nos possuirmos sempre e em todos os momentos no meio das múltiplas influências que vêm perturbar o existir perseverante. E assim dir-se-ia que um primeiro núcleo da crise se encontra sempre nas encruzilhadas onde o esforço para perseverar esperançadamente no nosso existir é cruzado por tendências sonâmbulas, de inércia, de desistência, de fuga ou de queda.

$\mathrm{Na}$ via de um aprofundamento da crise e da nossa procura de um critério distintivo, tais considerações não completam, no entanto, a nossa análise.

É necessário constatar, também do "lado de fora", o que faz determinada situação aparecer a um sujeito como "crise", pois se o único critério fosse, de facto, o existencial, a crise seria um estado permanente de todos e de cada um e, nesse caso, como diria P. Ricoeur, tudo sendo crise, nada seria crise. ${ }^{74} \mathrm{Em}$ função do que fica dito, não faria certamente sentido supor que se reconhece como situação de crise "fora de nós" algo de radicalmente diferente do que se vive como crise em nós; mas para completar o nosso critério identificador de crise é ainda necessário saber se algo do que foi dito sobre o plano pessoal pode ser transposto para o plano da realidade social e fornecer pistas para descobrir um critério ao mesmo tempo universal e transtemporal de crise, com o qual seja pertinente caracterizar um determinado período ou contexto histórico-social ${ }^{75}$.

74 RICOEUR, P., "La crise, ...", p. 12.

75 Ibidem, p. 13. Ricoeur propõe-nos este caminho na esteira de Landsberg e Mounier ; nós procurámos fazer o mesmo caminho a partir de Maine de Biran. 
A análise que vimos desenvolvendo do critério existencial de crise oferece-nos, nesse sentido, uma dupla indicação que merece ser explorada: por um lado a ligação entre crise e tempo ou temporalização; por outro, a ligação entre crise e firmeza ou afirmação.

Consideremos a primeira destas indicações, recordando a angústia de Biran aquando do episódio com a Duquesa de Rohan. Essa angústia guarda algo que não é apenas próprio do indivíduo Maine de Biran, mas revelador da condição humana - de uma condição que é marcada pelo conflito de se querer ser si mesmo num mundo com outros. "Olho-me, vejo-me nas minhas ações e julgo-me" à luz da imagem que terei de mim mesmo e do que os outros poderão vir a pensar de mim. E por isso sou crise no sentido em que, para mim, reapossar-me da minha personalidade é sempre algo que acontece num presente que é, ao mesmo tempo, passado recente e futuro iminente. Quando me olho e me julgo na minha situação, faço-o sempre, pois, apropriando-me das minhas ações ainda presentes mas já repercutindo-se numa imagem - de desproporção - que é o meu ser futuro ${ }^{76}$.

Num certo sentido, é esta estrutura de temporalização que, como mostra Ricoeur, pode ser transposta para o âmbito global da consciência histórica ao mesmo tempo acentuando, fazendo variar produtivamente e relativizando a polaridade, proposta por Koselleck, entre "horizonte de espera" e "espaço de experiência" ${ }^{\prime 7}$. Nesta relação, onde o aluno de Heidegger faz ressoar a distinção augustiniana entre presente do passado - a memória - e presente do futuro - a espera -, as duas categorias históricas destacadas são assim ponderadas: o "espaço de experiência" corresponde ao "passado atual cujos acontecimentos foram integrados e podem ser rememorados ${ }^{78}$; o "horizonte de espera" designa a preocupação pelo futuro e liga-se "ao que-ainda-não-é, ao que-não-é-do-espaço-de-experiência, ao que-não-é-ainda-senão-expectável."79 E o centro da análise é localizado na distância que existe entre os dois, fazendo do presente um movimento de temporalização que avança à medida da tensão entre o realizado

76 Ibidem, p. 12.

77 Ibidem, p. 13.

78 KOSELLECK, R., Le futur passé, contribution à la sémantique dês temps historiques, (trad. franc.), Editions de l'Ehess, 1990, p. 311.

79 Ibidem, p. 311, Cf. CERCLET, D., "Le corps en mouvement comme lieu de constitution du temps?», in BERTHOZ, A. ANDRIEU, B., (dir.) Le corps en acte, P. U.N., 2010, p. 174. 
no campo de experiência e o realizável no horizonte de espera. Nestas categorias, que entrecruza com as suas análises da ideologia e da utopia, Ricoeur crê encontrar o ponto de apoio para meditar um conceito "ao mesmo tempo geral e determinado da crise". Tal conceito resume-o o filósofo neste termos: "quando o espaço de experiência se estreita por causa de uma negação geral de toda a tradição, de qualquer herança, e o horizonte de espera tende a recuar para um futuro cada vez mais vago e mais indistinto, apenas povoado de 'ucronias' sem influência sobre o curso efetivo da história, então a tensão entre horizonte de espera e espaço de experiência torna-se rutura, sisma." ${ }^{80}$

Neste sentido, então, a crise será como que uma "patologia do processo de temporalização da história", que se pressente existencialmente como sentimento claustrofóbico, como vivência de uma rutura bloqueadora do processo de temporalização pessoal, como abismo entre o realizado e o realizável. Dito de outro modo, crise é, ainda segundo Ricoeur, "uma disfunção da relação normalmente tensa entre horizonte de espera e espaço de experiência." ${ }^{81}$ Pode ser dito de crise, pois, um contexto social ou político onde as forças perseverantes do presente e as memórias do realizado não vislumbram no horizonte de futuro senão forças de inércia, de repetição, de deserção, forças incapazes de pôr em marcha as promessas que se desenham no "presente do futuro", ou de sequer abrir espaço ao poder transformador da imaginação.

O que nos leva à segunda indicação do critério existencial de crise que propusemos: o sentimento de recorrente falta de firmeza, de pontos de apoio que disponibilizem o plano de consistência necessário ao reapossamento das possibilidades humanas de existir. Com o critério existencial, reconhecemos a crise na oscilação melancólica entre momentos de concentração e posse de si e momentos de "perda do seu centro". Neste sentido, poderia dizer-se que o reconhecimento da crise se liga à consciência de poder não ser si mesmo em todos os momentos, ao escândalo de, subitamente e sem aviso, podermos perder-nos de nós próprios; mas também à estranheza de nos reconhecermos depois de não ter sido. Assim se constrói um existir constantemente averiguado entre o que se conquista de si e subitamente se pode perder, constantemente medido entre a

\footnotetext{
${ }^{80}$ RICOEUR, P., "La crise, ...", p. 13

81 Ibidem, p. 14.
} 
firmeza do que se alcança e o pressentimento da sua precariedade cujas causas "em mim" permanecem refractárias à consciência.

De algum modo, esta estrutura de oscilação precária dos pontos de apoio, variando, segundo Biran, entre o exercício da vontade e a influência selvagem do fluxo afetivo - onde se pressagia a preponderância cega da vida e dos outros - pode ser transposta para o âmbito global da consciência histórica acentuando aquilo a que D. Innerarity chamou, na contraluz de uma ideia de história como "peculiarização", a "aprendizagem da contingência." ${ }^{2}$ Não só os sujeitos, mas também as instituições e os sistemas sociais, têm um carácter e uma história não em função das suas intenções (ou da sua vontade) mas, em grande parte, "por efeito da intervenção das intenções de outros e dos acontecimentos contingentes para os quais não estão programados." ${ }^{83} \mathrm{O}$ aparecimento e comportamento destes últimos são "aleatórios em relação às intenções, planos e evolução normal do sujeito" ${ }^{84}$, muitas vezes manifestando propriedades anómalas e surgindo de inesperadas combinações singulares que frustram amiúde as expectativas da vontade. O sentimento de crise cresce nestes esgueires de inesperado, de insegurança, de efetiva desconcentração resultante de um processo histórico impossível de padronizar e calcular sem erro. Numa palavra, longe de sermos os mestres e possuidores da nossa história, são antes aqueles processos em grande parte aleatórios e que escapam às expectativas, que se furtam à previsão, ou subvertem as regras e o habitual que nos mostram quem somos ${ }^{85}$.

Por isto se compreende que o modo que corresponde à história não poderia senão ser narrativo ${ }^{86}$ : porque apenas a narrativa guarda o poder de integrar coerentemente os acontecimentos que não encaixam em qualquer modelo teórico, que subvertem qualquer expectativa racional, qualquer padronização. Por isso quando por exemplo "alguém se procura desculpar, costuma contar uma história; isto é: remete-nos para circunstâncias que não obedecem às razões da sua ação." ${ }^{87}$ Tal não significa, no entanto, que tal história nos possa "exonerar

\footnotetext{
82 INNERARITY, D., O Novo Espaço Público (trad. port.), ed. Teorema, 2006, pp. 187 e ss.

83 Ibidem, p. 185.

84 Ibidem, p. 188.

85 Cf. Ibidem, p. 191.

86 Ibidem, p. 189.

87 Ibidem, p. 188.
} 
do difícil exercício das nossas liberdades"; longe disso, a lição a retirar do gesto narrativo é a de que devemos moderar as certezas sobre o futuro, libertar-nos da ilusão de que dado "sinal da história" revela mais necessidade do que simples acaso, mais firmeza do que apenas variação - e compreender que o futuro se mantém aberto como realidade não exaurível e nunca definitivamente firme.

Assim, o mais apreciável ensinamento da dimensão narrativa da história seria o de nos tornar possível "adivinhar quão indeterminadas estão as possibilidades do que viermos a ser" ${ }^{\prime 8}$. E, neste sentido, o critério da crise seria o de uma "patologização" do carácter aberto da história: ou melhor a ocupação do seu carácter de abertura quer pela pura incerteza, face à qual se cai na desistência alienante, quer pelo vazio de possibilidades razoáveis, ante o qual sucumbem a vontade e a projeção de possíveis. A crise seria, portanto, de um modo ou de outro, uma situação de carência de possibilidades de fazer sentido orientador o que permite afirmar que neste contexto se jogam sempre, como viu Ricoeur, três traços que podemos recuperar do modelo médico de crise: a) uma patologia cujo sintoma principal é o de um mal-estar, o de um sofrimento que resulta da aparente impossibilidade de integrar os acontecimentos passados num espaço de experiência presente, em vista de uma antecipação orientadora do futuro; b) um constante ciclo de ruturas, de quedas súbitas, que tornam impossível a consistência do tempo; c) a expectativa sempre adiada de um diagnóstico convincente; d) a oscilação constante entre a esperança de cura e a fatalidade do fim.

\section{Filosofia, crise e sentido}

Mas como enfrentar tais situações? Ou seja: qual a solução para a crise? Este questionamento, esperado por todos os conferencistas, pode ser formulado em vários tons, como reconheceu ironicamente N. Postman: há aqueles que perguntam com grande ansiedade, supondo que o conferencista conhece as soluções tão bem como os problemas mas não as quer revelar; há aqueles que perguntam ameaçadoramente, certos de que o conferencista não deveria sequer ter aparecido para maçar as pessoas sem uma resposta pronta e definitiva para os problemas

88 Ibidem, p. 191. 
que formula; e, finalmente, há aqueles que perguntam de modo encorajador, reconhecendo que para problemas tão complexos não há soluções simples, mas que, ainda assim, do debate crítico alguma orientação, algum sentido, pode emergir $^{89}$. A estes últimos me atreverei propor algumas notas orientadoras, que mais não farão, seguramente, do que mostrar a minha própria perplexidade e desorientação ante a dificuldade do problema debatido.

Uma primeira nota orientadora pretende chamar a atenção para o seguinte facto: no centro da crise, onde nascem as suas forças mais paralisantes, mais alienadoras, mais negadoras de futuro, também nasce o que nos pode salvar: a vocação da crise para se oferecer como ocasião de questionamento das aparências, de investigação crítica do que realmente vale, de transformação de princípios e normas, de renovação das tradições mais férteis e dos caminhos que guardam mais promessas de futuro. Há que aprofundar a crise, pois, no sentido de assumir o seu escândalo como ocasião de crítica - de crítica às formas empobrecidas de fazer sentido que tendem a reduzir o inacabamento próprio do futuro à aridez do mesmo.

Segunda nota: tal capacidade de crítica exige o esforço de uma aprofundada compreensão dos problemas, de uma complexificação dos discursos e de densificação de possibilidades novas de sentido. Dir-se-ia que uma situação de crise reclama Filosofia enquanto esta sempre se propõe como saber que: a) se compromete com a autenticidade; b) critica a aparência, o banal e o monótono; c) afirma e defende a irredutibilidade da diferença; c) nega a uniformização do sentido sob a forma de produto, função ou mercadoria.

Terceira nota: o esforço de complexificação filosófica deverá estar ao serviço de uma aproximação epistemológica e psíquica à ideia de que não há apenas um único sistema de pensamentos capaz de produzir a verdade, de propor o progresso e de aumentar a posse de si, mas vários. O mesmo é dizer que devemos encarar seriamente as propostas das grandes análises filosóficas, como das grandes narrativas literárias, históricas e religiosas, devemos ouvir o que nelas ainda nos fala e pode contribuir para compreender a nossa situação presente

89 POSTMAn, N., Tecnopolia (trad. port.), ed. Difusão Cultural, 1994, p. 160. Este texto foi ainda inspirador de alguns aspetos das notas que se seguem. 
sempre aberta a um futuro por fazer - numa palavra devemos aplicá-las (no sentido hermenêutico do termo) a uma causa que valha a pena.

Quarta e última nota: encarar tais propostas e procurar apropriá-las, aplicá-las à orientação da ação, conduzirá a reconhecer não ser mais possível dar demasiada atenção às opções de sentido empobrecido (derivadas de sondagens, estudos de opinião, ratings, racionalização burocrática, lixo televisivo, excesso de informação superficial, monotonia do politicamente correto, estagnação do discurso político, desorientação do discurso económico, compartimentação artificial de saberes, má literatura, arte desinteressante, etc.) sem interpretar cuidadosamente os respetivos pressupostos, preconceitos e, principalmente, limites. Neste sentido, é necessária uma dupla tarefa quotidiana: por um lado, preservar a capacidade crítica e o pensamento razoável; por outro, recusar o critério da eficácia como prioritário na determinação das relações humanas, da organização do estado, e da educação do pensar. 